\title{
What makes a text interesting? Interest-evoking strategies in expository text from Russian school textbooks
}

\author{
Larisa A. PIOTROVSKAYA and Pavel N. TRUSHCHELEV
}

The Herzen State Pedagogical University of Russia

Saint Petersburg, Russia

\begin{abstract}
The article provides the linguistics approach to the study of text-based interest. The purpose of the article is to identify the means and strategies used in expository texts from Russian school textbooks for the creation of text emotiveness. This characteristic of "an interesting text" has been repeatedly pointed out in the psychological research (Schiefele 2009). The article uses the linguistics methods of communicative and functional analysis and, in particular, the method of semantic modeling of emotive situations (Filimonova 2007). The authors' intention "to evoke the reader's interest" is the basis for forming an emotional-evoking type of expository discourse. The implementation of this intention is carried out through special discourse strategies called interest-evoking rhetorical strategies. Some of these strategies are based on the transmission of emotions as a special type of information in verbal interaction. In a text, this type of information is represented by emotiveness, that is, a component of text content through which the emotional states of participants of communication or characters are manifested. The article provides a description of four primary ways to create expository text emotiveness: 1) the usage of emotive insertions - commentaries made by the participant of communication acting as the subject who feels emotions; 2) the verbalization of the emotional scenario of interest for its projection to the reader; 3 ) the description of the characters' emotional states; 4) the representation of "abnormal" situations (a disruption of normal and expected relations between components of a situation in the real world described in a text). The first two ways are related to the strategies of the text dialogization aimed at creating the dialogue form of an expository text, and the thematization of interest. The third way enhances the text vividness and the fourth increases its dynamics and unexpectedness for the reader.
\end{abstract}

Keywords: emotiveness, evoking emotions, emotive pragmatics, expository text, interest, emotive discourse

\section{For citation:}

Piotrovskaya, Larisa A. \& Pavel N. Trushchelev. 2020. What makes a text interesting? Interest-evoking strategies in expository text from Russian school textbooks. Russian Journal of Linguistics 24 (4). 991-1016. DOI: 10.22363/2687-0088-2020-24-4-991-1016 
Научная статья

\title{
Что делает текст интересным? Языковые способы повышения эмоциогенности учебных текстов
}

\author{
Л.А. ПИОТРОВСКАЯ, П.Н. ТРУЩЕЛЁВ
}

Российский государственный педагогический университет имени А.И. Герцена Санкт-Петербург, Россия

\begin{abstract}
Аннотация
В статье предлагается лингвистический подход к изучению способов формирования эмоции интереса в тексте (так называемый “text-based interest”). Цель статьи - выявить средства и стратегии, используемые авторами учебных текстов для создания эмотивности текста. Эмоциогенность такой характеристики «интересного текста», как его эмотивность, неоднократно отмечалась в психологических исследованиях (Schiefele 2009). Для достижения поставленной цели используются методы коммуникативно-функционального анализа текста, в частности метод семантического моделирования эмотивных ситуаций (Филимонова 2007). Намерение авторов учебных текстов каузировать интерес у читателя лежит в основе формирования эмоционально-эвокативного типа учебного дискурса. Для реализации данного намерения авторы используют различные дискурсивные стратегии, часть из которых основывается на передаче в речи эмоций как особого типа информации. В тексте данный тип информации представлен эмотивностью текста - компонентом его смысловой структуры, посредством которого манифестируются эмоциональные переживания субъектов речи и персонажей текста. Выделено четыре основных приема создания эмотивности учебного текста: 1) использование эмотивных вкраплений - комментариев чего-либо с эмоциональной точки зрения (носитель эмоционального переживания - адресант и/или адресат); 2) вербализация эмоционального сценария интереса с целью его проецирования на адресата; 3) описание эмоциональных переживаний третьих лиц (персонажей текста); 4) репрезентация «ненормальных» ситуаций (нарушение нормальных и ожидаемых отношений между компонентами фрагмента действительности, отраженного в тексте). Первые два приема связаны со стратегиями диалогизирования, нацеленного на формирование диалогового характера учебного текста, и тематизации эмоции интереса. Третий прием позволяет усилить наглядность и яркость изложения, а четвертый - его динамичность и неожиданность для читателя.
\end{abstract}

Ключевые слова: эмотивность, эмоџиогенность, эмотивная прагматика, учебный текст, интерес, эмотивный дискурс

\section{Для цитирования:}

Пиотровская Л.А., Трущелёв П.Н. Что делает текст интересным? Языковые способы повышения эмоциогенности учебных текстов. Russian Journal of Linguistics. 2020. Т. 24. № 4. C. 991-1016. DOI: 10.22363/2687-0088-2020-24-4-991-1016

\section{1. Введение}

В психологической литературе эмоция интереса, или любопытство, трактуется как специфическое положительное переживание, «исследовательский импульс», связанный с потребностью и мотивацией узнать что-то новое об объекте интереса, с повышенным вниманием к нему (Рубинштейн 2001: 525-528, Silvia 2006: 23-29). Эта эмоция играет важнейшую роль в процессе обучения, поскольку составляет основу познавательной деятельности (Izard 
2007: 271), является первым этапом становления индивидуальных интересов человека (Hidi 2006) и создает «психологически комфортный режим умственного труда» (Холодная, Гельфман 2016: 51). Поэтому в настоящее время меняются требования к школьным учебникам: специалисты полагают, что учебный текст должен быть не просто понятным для читателя, но и интересным, т.е. должен вызывать эмоцию интереса, быть эмоциогенным (Там же: 36-40).

Считается, что интерес вызывает прежде всего что-то новое, неоднозначное и необычное (Silvia 2006: 42). Зарубежными психологами выделены более 20 характеристик текста, способных каузировать интерес у читателей (такой тип интереса называют «text-based interest») (Shraw \& Lehman 2001, Silvia 2006: 77-82, Wade, 2001). В настоящее время выделяют шесть основных характеристик: новизна и неожиданность (surprisingness), значимость, когерентность (к ней психологи относят и легкость понимания текста, и особенности его организации), яркость и динамичность изложения (vividness), конкретность, абсолютно интересные темы (смерть, насилие, секс и др.) (Schiefele 2009, Schraw \& Lehman 2001). У. Шифель, кратко обобщая исследования «интересного текста», приходит к выводу, что «хорошо организованные и понятные тексты с конкретной, неожиданной и яркой информацией повышают читательский интерес» ${ }^{1}$ (Schiefele 2009: 199).

Из сказанного следует, что психологи учитывают в том числе и такие характеристики текста, которые связаны исключительно с фактором интерпретатора (например, новизна или легкость понимания). Кроме того, большинство признаков «интересного текста» являются, по сути, характеристиками его содержания. Это в известной степени отражает речевую деятельность читателя, которую можно представить как процесс построения ментальной модели содержания текста (Залевская 2001: 120-152). В то же время такой подход не позволяет достаточно полно описать реальные авторские стратегии развертывания текста, ориентированные на каузацию интереса. С. Хайди и У. Бэрд еще в 1988 г. обратили внимание на важность изучения таких стратегий, предложив для их обозначения специальный термин - «interest-evoking rhetorical strategies» (Hidi \& Baird 1988: 480). Однако до сих пор данный вопрос не получил должного внимания в лингвистических исследованиях.

В настоящей статье предлагается лингвистический подход к изучению таких стратегий, основанный на положениях лингвистики эмоций (в российской науке для обозначения этой научной области В.И. Шаховским был предложен специальный термин - эмотиология) (Шаховский 2008: 21). Согласно предлагаемому подходу сравнительный лингвистический анализ учебных текстов с учетом результатов психологических исследований позволяет выявить и описать конкретные способы формирования эмоции интереса в тексте. Ранее нами были описаны способы диалогизирования и конкретизации содержания учебных текстов (Пиотровская, Трущелёв 2018, Трущелёв

1 “...well-organized and comprehensible texts with concrete, surprising, and vivid information enhance text-based interest”" (Schiefele 2009: 199). 
2019), а также экспериментально доказана их релевантность формированию эмоции интереса у читателя-школьника (Пиотровская, Трущелёв 2019).

Настоящая статья посвящена описанию способов создания эмотивности учебного текста, которая, по мнению ряда психологов (Kintsch 1980, Schifele 2009, Wade 2001), является одной из эмоциогенных характеристик текста. Для лингвистического анализа учебных текстов предлагается использовать методы, разработанные в одном из актуальных направлений современной эмотиологии - текстолингвистики эмоций (см. Шаховский 2008: 180-256).

Материалом исследования послужили учебные тексты объемом более 350000 словоупотреблений из российских учебников для средней школы (7-9 кл.) по истории, обществознанию, русскому языку, физике и биологии. В настоящее время все эти учебники рекомендованы Министерством образования и науки Российской Федерации к использованию в образовательных учреждениях.

\section{2. Теоретические положения}

Ключевое для эмотиологии понятие эмотивности в зарубежных исследованиях долгое время рассматривалось с точки зрения намерений адресанта оказать эмоциональное воздействие на адресата (Stankiewicz 1964, Daneš 1982). Так, чешский ученый Ф. Данеш одним из первых предложил разграничить термины «эмоциональный» и «эмотивный» следующим образом: «эмоциональный» - 'имеющий отношение к выражению эмоций самого субъекта речи', а «эмотивный» - 'имеющий отношение к намерению говорящего оказать воздействие на адресата' (Daneš 1982: 93-94). Показательно, что даже намеренное выражение эмоций в речи рассматривалось как способ эмоционального воздействия на адресата (Stankiewicz 1964).

Впоследствии термины «эмотивность» и «эмоциональность» зарубежными учеными стали использоваться как синонимы. По всей видимости, это связано с активной разработкой проблемы «язык и эмоции» в рамках направлений, изучающих коммуникативный контекст ситуации речевого взаимодействия, - психолингвистики и дискурс-анализа.

В отечественной эмотиологии с момента ее появления, напротив, принято разграничивать понятия «эмотивность» и «эмоциональность». По мнению Шаховского, эти термины обслуживают различные дисциплины: лингвистику - с одной стороны, психологию и философию - с другой (Шаховский 2009/1987: 24). При этом эмотивность коррелирует прежде всего с намерениями адресата выразить свои эмоции. Так, согласно семантическому подходу, эмотивность - это «имманентно присущее языку семантическое свойство выражать системой своих средств эмоциональность как факт психики» (Там же: 24).

Бурное развитие эмотиологии в конце XX - начале XXI вв. позволило расширить понимание эмотивности как в зарубежной, так и в отечественной науке. Поэтому в настоящее время можно говорить о «широкой» трактовке 
данного понятия, которое связывается с каузацией эмоций, их концептуализацией в языке и манифестацией в речи (Ионова 2015, Alba-Juez, Larina 2018, Alba-Juez \& Mackenzie 2019, Macagno 2014). Такая трактовка принята прежде всего в исследованиях, посвященных эмотивному дискурсу - дискурсу ${ }^{2}$, имеющему «некоторое эмоциональное содержание или эффект» ${ }^{3}$ (Koschut 2017: 277, см. также Edwards 1999). Анализ эмотивного дискурса в основном направлен на изучение того, как адресант использует эмотивный код языка в различных коммуникативных ситуациях и как различные эмоциональные ситуации концептуализируются в эмотивном коде языка (Ионова 2015, Alba-Juez, Larina 2018, Alba-Juez \& Mackenzie 2019, Koschut 2017).

Т. Кэтрел выделяет три типа эмотивного дискурса (ученый называет их «emotionally laden discourses»), отражающих три типовые ситуации эмоционального речевого взаимодействия: дискурс об эмоциях (a discourse on emotions), эмоциональный дискурс (an emotional discourse) и эмоциональноэвокативный дискурс (an emotion-evoking discourse) (Katriel 2015: 57-58). Первые два типа связаны с передачей в речевом общении эмоций как особого типа информации. Дискурс об эмоциях, который в отечественной эмотиологии принято обозначать как «описание эмоций в речи» (Пиотровская 2015: 780), содержит описание чьих-либо эмоциональных состояний или рассказ о каких-либо эмоционально насыщенных событиях (например, Мне было грустно). Эмоциональный дискурс (точнее - собственно эмотивный дискурс) подразумевает непосредственное выражение эмоций субъекта речи (например, Тоже мне герой!), которое может осуществляться тремя способами, выделенными нами ранее: 1) выражение эмоций в речи при доминировании рациональной оценки над эмоциональной, 2) выражение эмоций в речи при доминировании эмоциональной оценки над рациональной, 3) отражение эмоций (неконтролируемое проявление эмоций) (Там же). Особый и наименее изученный тип дискурса - это эмоционально-эвокативный дискурс, который можно рассматривать в двух аспектах: с одной стороны, изучаются способы преднамеренного эмоционального воздействия, с другой - эмоциогенность текста как характеристика, зависимая и от его содержания (с учетом способов эмоционального воздействия), и от личности адресата (Маслова 1992: 185). В процессах речевого взаимодействия перечисленные типы дискурсов чаще всего представлены не изолировано, а в сочетании друг с другом (Katriel 2015: 63). Так, функциональный подход Э. Станкевича, по сути, был нацелен на изучение сочетания собственно эмотивного и эмоционально-эвокативного типов дискурса (Stankiewicz 1964).

Учитывая современное понимание лингвистики текста как одного из направлений дискурс-анализа (Alba-Juez 2016), а также изначальное развитие

${ }^{2}$ В данном случае речь идет о дискурсе в его традиционном понимании как единстве двух сущностей - «процесса языковой коммуникации и получающегося в ее результате объекта, т. е. текста» (Кибрик 2009: 4, см. также Alba-Juez 2016).

3 “...some affective content or effect” (Koschut 2018: 277). 
эмотиологии в рамках коммуникативно-функционального подхода (Шаховский 2009/1987), полагаем, что изучение эмотивности текста можно рассматривать как возможное направление исследований эмотивного дискурса, ориентированного на анализ его «эмоционального содержания» 4 . Опираясь на положения отечественной эмотиологии, мы рассматриваем эмотивность текста как компонент его смысловой структуры, имеющий план содержания и план выражения, посредством которого манифестируются (т.е. и описываются, и выражаются) эмоциональные переживания, носителями которых могут быть как субъект речи, так и персонажи текста (Бабенко 1989: 104-105, Шаховский 2008: 185-186). При этом, вслед за С.В. Ионовой, нами учитывается весь диапазон возможных эмоциональных переживаний: настроения, чувства, аффекты, собственно эмоции, страсть ${ }^{5}$. Таким образом, эмотивность текста связана с передачей эмоций как особого типа информации в речевом взаимодействии и, следовательно, может быть соотнесена с дискурсом об эмоциях и с собственно эмотивным дискурсом.

В то же время следует различать понятия «эмотивный текст» и «эмоциогенный текст», которым может быть любой текст, даже абсолютно неэмотивный (Маслова 1991: 185, Шаховский 2008: 181-182). Несмотря на то что можно с высокой долей вероятности прогнозировать реакции адресата, эмоциогенный эффект текста зависит в том числе и от фактора интерпретатора (Шаховский 2008: 181-182). При формировании эмоции интереса эмотивность учебного текста и его эмоциогенность коррелируют с эмотивной прагматикой текста, под которой, вслед за Шаховским, следует понимать «фактор адресата, с точки зрения преднамеренного эмоционального воздействия на него» (Шаховский 2009/1987: 27). Следовательно, понятие эмотивной прагматики текста можно соотнести с выделенным Кэтрел эмоциональноэвокативным дискурсом.

Таким образом, эмотивный учебный дискурс представлен эмоциональноэвокативным дискурсом, направленным на преднамеренную каузацию эмоции интереса у адресата. В свою очередь, эмоционально-эвокативный дискурс образуется в том числе из дискурса об эмоциях и эмотивного дискурса, которые становятся одним из «стратегических инструментов» 6 (Katriel 2015: 58) эмоционального воздействия.

В учебном тексте как продукте речевой деятельности объективируются в том числе и коммуникативные условия ее протекания (Зимняя 2001: 174): намерение адресанта оказать эмоциональное воздействие, т.е. каузировать эмоцию интереса, лежит в основе эмотивной прагматики текста. Эмотивная прагматика формируется посредством различных способов, одним из

${ }^{4}$ Об этом свидетельствует сравнение практически идентичных методов анализа, с одной стороны, эмотивности текста, с другой - эмотивности дискурса (напр., ср. Филимонова 2007: 83-88 vs. Koschut 2018: 278-288).

${ }_{5}^{5}$ Ионова С.В. Эмотивность текста как лингвистическая проблема: дис. ... канд. филол. наук: 10.02.19. Волгогр. гос. пед. ун-т. Волгоград, 1998. С. 16-17.

6 "strategic tool" (Katriel 2015: 58). 
которых является создание эмотивности учебного текста, направленное на увеличение его потенциальной эмоциогенности.

\section{3. Методология}

Впервые детальное исследование эмотивности текста было проведено под руководством Шаховского в диссертационной работе Ионовой, которая предложила в составе эмотивности текста выделять его эмотивное содержание (или план содержания эмотивности) и эмотивную окраску (или план выражения эмотивности); при этом эмотивное содержание текста находит отражение в его эмотивной окраске ${ }^{7}$.

Впоследствии для анализа эмотивного содержания текста О.Е. Филимоновой был разработан метод «проникающего изучения категории эмотивности» (Филимонова 2007: 83-88), направленный на семантическое моделирование представленных в тексте эмотивных ситуаций (ЭС) - ситуаций, когда некто испытывает какое-то эмоциональное состояние. По мнению ученого, инвариантная модель ЭС имеет следующий вид:

\section{S(n) feel $\operatorname{Emo}(\mathbf{n})$,}

где $\mathrm{S}$ - субъект, испытывающий эмоциональное состояние; $\mathrm{n}$ - возможное число субъектов или состояний, большее, чем единица; feel - указание на наличие у субъекта или субъектов определенного эмоционального состояния (Там же: 71).

Приведем простой пример.

(1) В душе мальчика [S] рано возникло чувство ненависти [Emo] коярам.

Полагаем, что можно уточнить представленную модель ЭС, дополнив ее модификатором, фиксирующим причину появления (каузации) определенной эмоции. Такая модель ЭС будет отражать в тексте типовую эмоциональную ситуацию появления любых эмоций у индивида (Апресян В.Ю., Апресян Ю.Д. 1995, Шаховский 2008: 129-133). Представим модель в следующем виде:

\section{$P$ caus $\rightarrow S(n)$ feel $\operatorname{Emo}(n)$,}

где P - субъект или положение дел, каузирующие (caus) определенную эмоцию у $\mathrm{S}$ - субъекта, испытывающего эмоциональное состояние, (S(n) feel $\operatorname{Emo}(\mathrm{n}))$.

При этом при реализации этой модели в тексте каузируемая эмоция, а также намерение субъекта-каузатора (если он есть) оказать эмоциональное воздействие могут не эксплицироваться. Приведем пример такой реализации модели.

(2) Царь приказал не снимать тела повешенных в течение нескольких дней. [ $\rightarrow$ для устрашения подданных].

\footnotetext{
${ }^{7}$ Ионова С.В. Указ. соч. С. 45-47.
} 
Используя терминологию прагматики, эксплицитно не выраженную часть модели можно рассматривать как импликатуру, которая также является частью содержания текста (van Dijk 2014: 283-285). Эта часть содержания становится известной адресату благодаря его знаниям конкретных категориальных эмоциональных ситуаций, или «эмоциональных сценариев» ${ }^{8}-$ реальных типичных ситуаций (последовательности событий, определенной деятельности и др.), во время которых кто-либо, как правило, испытывает определенные эмоции (Edwards 1999: 278-281, Шаховский 2008: 130, см. также Апресян В.Ю., Апресян Ю.Д. 1995: 458-459).

Кроме того, детализации требует субъектная составляющая модели ЭС. Л.Г. Бабенко первая предложила выделять в содержании текста модальные и диктальные эмоции в зависимости от их субъекта - адресанта или персонажа текста соответственно (Бабенко 1989: 104). Соглашаясь с данной точкой зрения, предлагаем расширить ее, используя субъектную модель, разрабатываемую Н.К. Онипенко (Онипенко 2013). С этой точки зрения в тексте можно выделить субъектов модуса (субъекты мыслящие, сфера 1-го и 2-го лица; носители модальных эмоций) и субъектов диктума (субъекты мыслимые, сфера 3-го лица; носители диктальных эмоций). Для наглядности представим описание субъектов эмотивного содержания текста в виде таблицы (табл. 1$)^{9}$.

таблица 1

Субъекты эмотивного содержания учебного текста

\begin{tabular}{|l|l|l|l|}
\hline \multicolumn{3}{|c|}{ Субъекты диктума } & \multicolumn{1}{c|}{ Субъекты модуса } \\
\hline $\mathbf{S}_{1}$ & \multicolumn{1}{|c|}{$\mathbf{S}_{\mathbf{2}}(\mathbf{P})$} & \multicolumn{1}{c|}{$\mathbf{S}_{\mathbf{3}}$} & \multicolumn{1}{c|}{$\mathbf{S}_{4}$} \\
\hline $\begin{array}{l}\text { субъект-персонаж, } \\
\text { испытывающий } \\
\text { эмоциональное } \\
\text { состояние }\end{array}$ & $\begin{array}{l}\text { субъект-каузатор (положение } \\
\text { дмли илорый своими действи- } \\
\text { рует определенное эмоцио- } \\
\text { нальное состояние }\end{array}$ & $\begin{array}{l}\text { субект-адресант, } \\
\text { испытывающий } \\
\text { состояние }\end{array}$ & $\begin{array}{l}\text { субъект-адресат, } \\
\text { испытывающий } \\
\text { эмоциональное } \\
\text { состояние }\end{array}$ \\
\hline
\end{tabular}

Table 1

The subjects of emotive content of expository text

\begin{tabular}{|l|l|l|l|}
\hline \multicolumn{2}{|c|}{ Thinkable subjects } & \multicolumn{2}{c|}{ Thinking subjects } \\
\hline \multicolumn{1}{|c|}{$\mathbf{S}_{\mathbf{1}}$} & \multicolumn{1}{|c|}{$\mathbf{S}_{\mathbf{2}}(\mathbf{P})$} & \multicolumn{1}{c|}{$\mathbf{S}_{\mathbf{3}}$} & \multicolumn{1}{c|}{$\mathbf{S}_{\mathbf{4}}$} \\
\hline $\begin{array}{l}\text { a character who } \\
\text { feels emotions }\end{array}$ & $\begin{array}{l}\text { causative subject (state of affairs) } \\
\text { which is a cause of an emotion }\end{array}$ & $\begin{array}{l}\text { a speaker who } \\
\text { feels emotions }\end{array}$ & $\begin{array}{l}\text { a recipient who } \\
\text { feels emotions }\end{array}$ \\
\hline
\end{tabular}

8 “emotional scenarios" (Edwards 1999: 278).

${ }^{9}$ Отметим, что нами не учитывается один субъект модуса - субъект-авторизатор, появление которого в субъектной перспективе текста чаще всего обусловлено трансформацией субъекта мыслимого в субъекта мыслящего, в восприятии которого представляется определенное положение дел (Онипенко 2013: 96-97). Такая трансформация позволяет автору погрузить читателя в мир переживаний и сознания персонажа текста. Однако, как показывают психологические исследования, эмоциогенность учебного текста не зависит от степени «погружения» читателя во внутренний мир текста (Kaakinen et al. 2018). Поэтому выделение субъекта-авторизатора в субъектной перспективе учебного текста в данной статье считаем нецелесообразным. 
Выделенные субъекты эмотивного содержания текста являются субъектами сугубо семантическими, и в этом главное отличие нашего подхода от подхода Н.К. Онипенко, направленного на описание субъектной перспективы текста на основе грамматической структуры образующих его высказываний. Однако субъекты эмотивного содержания текста воплощаются именно в субъектной перспективе текста, поэтому методы коммуникативной грамматики (Золотова и др. 2004: 229-353) позволяют достаточно точно идентифицировать представленных в тексте субъектов эмоциональных переживаний. Так, в примере (1) субъект эмоционального состояния (мальчик) выражается посредством осложненной модели субъектной синтаксемы «в + предложный nадеж» (Там же: 289). В зависимости от типа субъекта эмоционального переживания - субъекта модуса или диктума - предлагаем делить модели ЭС на модальные и диктальные соответственно. Так, в примерах (1) и (2) реализуются диктальные модели ЭС.

Эмотивная окраска текста - это «набор языковых и текстовых средств, используемых автором для кодирования эмоционального содержания» ${ }^{10}$. Это содержание может быть воплощено в тексте самыми различными способами (Шаховский 2008: 180-258), однако следует учитывать, что все эти способы должны позволять адресату идентифицировать ЭС в тексте. Поэтому, как правило, кодирование эмотивного содержания осуществляется посредством описания или моделирования эмоциональных сценариев. Для этого авторы часто используют эмотивные лексемы, при характеристике которых важно различать язык описания и язык выражения эмоций.

Язык описания эмоций является результатом концептуализации эмоций и представлен языковыми единицами, называющими эмоции (интерес, удивление, злость), и языковыми единицами, предназначенными для описания эмоциональных состояний (внешнего проявления эмоций (смех, плач), физиологического и психического состояния (усталость, стресс) и др.) (Шаховский 2009/1987: 98, см. также Бабенко 1989). Язык выражения эмоций - это единицы языка, имеющие эмотивный компонент значения, который служит для кодифицированного выражения эмоций субъекта речи (Шаховский 2009: 96-98). Так, в учебном тексте часто используются прилагательные с эмотивным компонентом значения (например, жалкий, славный).

\section{Пример анализа эмотивности текста}

Рассмотрим фрагмент текста из учебника по истории.

(3) Василий III приказал постричь бывщую жену в монахини. Соломония воспротивилась. Во время пострижения она $\left[\mathrm{S}_{1}\right]$ срывала с себя и топтала монашеское платье. Один из придворных $\left[\mathrm{S}_{1}\right]$ ударил ее плеткой: «Неужели ты противишься воле государя? Неужели медлишь исполнить его повеление?»

\footnotetext{
${ }^{10}$ Ионова С.В. Указ. соч. С. 47.
} 
В данном фрагменте выражены три диктальные ЭС.

Во-первых, здесь представлена ЭС, субъектом, которым является Соломония: $\mathbf{P}$ (заточение в монастырь) caus $\rightarrow \mathbf{S}_{1}$ (Соломония) feel $\mathbf{E m o}$ (отчаяние, недовольство). Ее эмоциональное состояние, обусловленное решением бывшего мужа заточить ее в монастырь, передается с помощью описания ее поведения, характерного для отраженного в тексте эмоционального сценария отчаяния и недовольства (срывала с себя и топтала монашеское платье).

Во-вторых, можно выделить ЭС, субъектом которой является придворный: P (поведение Соломонии) caus $\rightarrow S_{1}$ (придворный) feel Emo (удивление, возмущение). Его эмоциональное состояние, обусловленное поведением Соломонии, передается посредством прямой речи, в которой использован язык выражения эмоций, а именно эмотивные высказывания с частицей неужели (доминирование эмоциональной оценки над рациональной), предназначенные для выражения удивления (Пиотровская 1994: 92-93). Кроме того, описание поведения придворного (ударил ее плеткой), а также сама специфика удивления как «переходной эмоции» (Вотякова 2015: 120) позволяет уточнить эмоциональное состояние субъекта и обозначить его как «удивление, переходящее в возмущение» (Там же).

Выделенный тип эмотивных высказываний с частицей неужели выражает не только эмоциональное состояние говорящего, но и его эмоциональное отношение, которое может быть направлено в том числе и на каузацию эмоций (Пиотровская 1994: 61-62). Это дает нам основание выделить еще одну диктальную ЭС с имплицитным компонентом, направленную на каузацию эмоции стыда у Соломонии: $\mathbf{S}_{2}$ (придворный) caus $\rightarrow\left[\mathbf{S}_{1}\right.$ (Соломония) feel Еmo (стыд)].

В дальнейшем при рассмотрении конкретных ЭС мы сосредоточимся преимущественно на способах их реализации, т.е. на их эмотивной окраске.

\section{4. Диктальные эмотивные ситуации в учебном тексте}

Появление диктальных моделей ЭС в смысловой структуре учебного текста связано с намерениями авторов учебников рассказать об эмоциональных переживаниях третьих лиц. Данные модели требуют идентификации субъекта эмоционального состояния в субъектной перспективе текста, поэтому, как правило, они представлены в текстах из учебников по истории или же в микротекстах, в которых дается какая-либо историческая справка (например, история научного открытия или биография ученого). Модель данного типа ЭС выглядит следующим образом: $\mathbf{S}_{\mathbf{2}}(\mathbf{P})$ caus $\rightarrow \mathbf{S}_{\mathbf{1}}$ feel $\mathbf{E m o .}$

Иногда такая модель может стать темой целого микротекста, особенно в учебниках по истории. Приведем типичный пример такого микротекста.

(4) Очевидиы отмечали, что в ночь накануне сражения Наполеон $\left[\mathrm{S}_{1}\right]$ не спал. Он пристально вглядывался в темноту - туда, где горели костры, разведенные русскими солдатами. По-видимому, он опасался, что Кутузов может дать своим войскам приказ к отступлению [P]. Утром император был бодр и полон надежд на победу своей армии. 
В этом фрагменте носителем эмоционального состояния, обусловленного ожиданием предстоящего сражения, является французский император Наполеон. Эмотивная окраска представлена описанием поведения и внутренних переживаний императора (не спал, пристально вглядыввался, был бодр u полон надежд), которое осуществляется в том числе и с помощью языка описания эмоций (форма глагола опасаться).

В пределах целого микротекста диктальные ЭС также могут стать одним из ведущих мотивов, которые «определяют намерение автора "раскрасить" свой текст» (Шаховский 2008: 237), т.е. сделать его более выразительным, более выразительным и эмоционально насыщенным. Так, диктальные ЭС являются ведущими мотивами в примере (3). Для наглядности рассмотрим еще один фрагмент текста.

(5) В ночь на 25 ноября 1741 г. 31-летняя Елизавета посетила казармы преображенцев и призвала защитить «дело Петрово». Мятежная «принцесса» $\left[\mathrm{S}_{1}\right]$ в окружении солдат явилась в спальню регентии: «Сестрица, пора вставать!» Увидев вооруженных преображенцев во главе с «сестрицей», Анна Леопольдовна $\left[\mathrm{S}_{1}\right]$ только и смогла вымолвить: «Ax, мы пропали!»

В данном фрагменте можно выделить две диктальные модели, субъектами которой выступают Елизавета и Анна Леопольдовна. Эмоциональное состояние обоих субъектов манифестируется посредством прямой речи. В речи Елизаветы используется эмоционально окрашенное высказывание с маркером восклицательности (доминирование рациональной оценки над эмоциональной), где также представлен деминутив-обращение (сестрица), который относится к средствам выражения эмоций (Volek 1987: 159). В речи Анны Леопольдовны представлено эмотивное высказывание (доминирование эмоциональной оценки над рациональной) с еще одной языковой единицей, предназначенной для выражения эмоций, - междометием $a x$.

Как видно из приведенных примеров, реализация диктальных ЭС в пределах целого микротекста требует значительной детализации изложения, что не всегда возможно и допустимо в учебных текстах. Поэтому намного чаще диктальная модель реализуется только в пределах одного высказывания, как показано в примерах (6) и (7), где используется язык описания эмоций, и в примере (8), в котором эмоциональное состояние субъекта манифестируется посредством прямой речи с эмоционально окрашенным высказыванием (доминирование рациональной оценки над эмоциональной).

(6) Люди $\left[\mathrm{S}_{1}\right]$, проживающие в этой местности, очень боятся новых катастроф $[\mathrm{P}]$.

(7) Вид восставших подданных $[\mathrm{P}]$ привел царя $\left[\mathrm{S}_{1}\right]$ в ужсас.

(8) Встретившим его придворным на вопрос о том, где же армия, он $\left[\mathrm{S}_{1}\right]$ был вынужден ответить: «Армии больие нет!» [P].

Кроме того, часто в пределах одного высказывания фиксируется только эмоциональное состояние субъекта диктума с помощью референтной 
именной группы, построенной по схеме атрибут (язык описания эмоций) + имя (субъект эмоционального переживания): встревоженные люди, взбешенный хан, озлобленные бояре.

Диктальные ЭС связаны с такой характеристикой «интересного текста» как яркость его изложения (vividness): они придают содержанию текста больше наглядности, каузируя тем самым интерес читателя. Значимость этой характеристики «интересного текста», особенно подчеркивается в исследованиях С. Уэйд, основанных на результатах анализа интервьюирования реципиентов (Wade 2001). При этом следует отметить, что эмотивная прагматика диктальных ЭС в учебном тексте отличается от эмотивной прагматики ЭС в нарративном, художественном тексте. Эмоциогенность учебного текста связана с вовлечением учащегося в учебный процесс, т.е. в процесс приобретения знаний, а эмоциогенность нарративного с текста - с погружением читателя в «мир текста» (Kaakinen et al. 2018). Поэтому в учебном тексте диктальные ЭС прежде всего связаны с активизацией дополнительных когнитивных ресурсов адресата (например, наглядно-образного мышления), а не с моделированием увлекательного фикционального мира художественного произведения.

Важно отметить, что можно выделить две основные функции диктальных ЭС с точки зрения их роли в процессе текстообразования. Во-первых, они могут быть одним из способов организации повествования, указывая на причину определенных событий. Так, в примере (7) носителем эмоционального состояния является царь Алексей Михайлович, который, испугавшись восставших, пошел на переговоры с ними (события Соляного бунта 1648 года). Однако, как показывает сопоставительный анализ учебных текстов, гораздо чаще диктальные ЭС представляют собой седактивные детали (примеры (4), (5), (8)) «интересные, но незначимые детали, не являющиеся необходимыми для достижения учебных целей» ${ }^{11}$ (Rey 2012: 217). В настоящее время считается, что седактивные детали могут препятствовать адекватному пониманию учебного текста (см. специальный выпуск журнала Applied Cognitive Psychology 2019).

\section{Ненормальные диктальные эмотивные ситуации}

Особый тип ЭС - это ненормальная ситуация. При изучении эмотивности текста данный тип ситуаций впервые был описан В.И. Болотовым (1981). Ненормальная ситуация - это нарушение нормальных и ожидаемых отношений между компонентами действительности (пространственных, временных, причинных, социальных и др.), отраженными в содержании текста (Болотов 1981: 23-38). Сам Болотов, как впоследствии и Ионова (она обозначала ненормальные ситуации термином «категория ненормы»), ${ }^{12}$ рассматривали ненормальные ситуации как один из способов эмоционального воздействия на

11 "....interesting but irrelevant details that are not necessary to achieve the instructional objective" (Rey 2012: 217).

${ }^{12}$ Ионова С. В. Указ. соч. С. 40. 
адресата текста. На наш взгляд, такие ситуации также являются частью эмотивного содержания текста.

Отнесение данных ситуаций к эмотивным можно объяснить с точки зрения деятельностных теорий эмоций, которые традиционно развивались в отечественной науке. В процессе деятельности индивида ненормальная ситуация является всегда эмоциогенной, поскольку приводит к переоценке прогнозируемого результата деятельности (Юматов и др. 2017: 18-29). Таким образом, ненормальные ситуации в тексте могут рассматриваться как разновидность эмоциональных сценариев.

Диктальную модель ненормальной ЭС можно представить как $\mathbf{P}$ caus $\rightarrow \mathbf{S}_{\mathbf{1}}$ feel $\mathbf{E m o}$, где $\mathbf{P}$ - ненормальное с точки зрения субъекта диктума положение дел. Как и другие диктальные ЭС, данная ситуация представлена преимущественно в учебных текстах с элементами повествования (прежде всего в текстах из учебников по истории).

Простейший способ фиксации ненормальной ЭС в тексте - это описание как самой ситуации ненормы, так и эмоциональной реакции на нее. В этом случае реализация модели ненормальной ЭС ничем не отличается от реализации других диктальных моделей ЭС, рассмотренных выше (см. пример (5)). В связи с этим, на наш взгляд, особое внимание следует уделить таким способам реализации ненормальных ЭС, при которых в тексте не фиксируется эмоциональное состояние субъектов диктума.

Иногда такая ненормальная ситуация может стать одним из главных текстообразующих мотивов. Так, в учебниках по истории России при описании правления императора Павла I (1796-1801 гг.) экспликация ненормальных ситуаций фактически организует все повествование: «ненормальная» жизнь наследника престола $\rightarrow$ «ненормальные» реформы $\rightarrow$ «ненормальная» внешняя политика $\rightarrow$ «ненормальная» смерть императора (убийство дворянами). Проиллюстрируем это на одном из фрагментов текста, посвященного правлению Павла I.

(9) Неуравновешенный и непостоянный в поступках и мыслях, Павел I доводил свои начинания до абсурда. В итоге вместо порядка кругом царил беспорядок, вместо закона - произвол. Венцом подобного управления стало появление в одно утро сразу трех взаимоисключаюмцих законов.

Ненормальность представленной ситуации выражается посредством характеристики Павла I (ненормальныцй, неуравновешенный), тематических лексем абсурд, беспорядок, а также с помощью приема контраста (порядок беспорядок, закон - произвол), который позволяет противопоставить ожидаемые результаты и реальные.

Нередко в учебных текстах ненормальные ЭС содержат семантику внезапности, которую можно представить в виде двух аспектуально-таксисных ситуаций: «длительность $\rightarrow$ внезапное/неожиданное наступление факта» (пример (10)) и «желание, готовность, наличие предпосылок для того, чтобы 
совершилось событие или осуществилось действие $\rightarrow$ наступление факта, препятствующего их осуществлению» (пример (11)) (Аверьянова 2010). При реализации первого типа ситуации может быть представлена «темпоральная рамка внезапности» (Там же), как в примере (10), где в качестве такой рамки выступает наречие неожиданно. При реализации второго типа ситуации автор может использовать прием контраста, основанный на противопоставлении ирреальной и реальной модальностей, т.е. потенциального и актуального значений (Бондарко и др. 1990: 72). Так, в примере (11) в первом предложении представлена категориальная модальная ситуация «ситуативно обусловленной возможности» (термин Е.И. Беляевой (Бондарко и др. 1990: 135)), выраженная с помощью вводного слова казалось, однако во втором предложении посредством отрицания и противительного союза но указывается исход данной потенциальной ситуации - ее нереализованность.

(10) Анна Иоанновна оставила трон так же неожиданно, как и заняла ezo.

(11) Казалось, для Шуйского самое худшее закончилось. Но это было не так. Пока из Тушина исходила угроза, Шуйского по необходимости терпели; но вот угроза миновала - и непопулярный царь стал никому не нужен.

Намного чаще семантика внезапности не эксплицирована вовсе и, следовательно, является импликатурой, которую читатель «восстанавливает», используя фоновые знания. Так, в примере (12) ненормальность ситуации определяется фоновыми знаниями читателя о том, что начать вторжение без объявления войны - это внезапно и «ненормально».

(12) В ночь на 12 июня 1812 2. без объявления войны Наполеон начал вторжение в предель России.

В то же время нужно учитывать, что ненормальное положение дел, в конечном счете, должно быть идентифицировано читателем (Болотов 1981: 12-19). По всей видимости, без специальных «маркеров» (например, выражающих семантику внезапности) «ненормальность» многих ситуаций не всегда может быть однозначно определена читателем-школьником.

Исследования Болотнова (1981) и Ионовой ${ }^{13}$ явно свидетельствуют о том, что ненормальные ситуации увеличивают общий эмоциогенный потенциал текста. Каково же их влияние именно на эмоцию интереса? Ненормальные диктальные ЭС, в отличие от «обычных», направлены не столько на усиление наглядности изложения, сколько на формирование «захватывающего сюжета», динамичности текста, что также делает изложение более ярким (vividness). Однако данный тип ЭС можно связать и с такой характеристикой «интересного текста», как его неожиданность для читателя (surprisingness). Именно этот аспект эмотивности текста подчеркивали У. Кинч (Kintsch: 1980), а также Г. Шроу и С. Леман (Schraw \& Lehman: 2001).

\footnotetext{
${ }^{13}$ Ионова С.В. Указ. соч.
} 


\section{5. Модальные эмотивные ситуации в учебном тексте}

Эмотивность подавляющего большинства учебных текстов по всем дисциплинам проявляется в виде эмотивных вкраплений, под которыми понимаются комментарии какого-либо события «с эмоциональной точки зрения» (Филимонова 2007: 270). Такие комментарии соответствуют модели $\mathbf{P}$ caus $\rightarrow$ $\mathbf{S}_{3}$ (aвTop) feel Emo, где P - некое положение дел, фиксируемое в учебном тексте. При этом субъект-адресант может быть не эксплицирован в субъектной перспективе текста, и отнесение к нему эмоциональных переживаний происходит автоматически. Как правило, субъект модели испытывает эпистемические эмоции - удивление, изумление, интерес.

Эмотивная окраска данных ЭС преимущественно представлена словами с эмотивным компонентом значения - прилагательными и словами категории состояния (страшно представить; иудовищные последствия) и эмотивнокаузативными прилагательными и причастиями (изумительные открытия; захватывающие события; печальная судьба). Кроме того, нередко в учебном тексте используются вербализованные эмотивные модусные рамки (Жаль, что люди не понимают этого...; Неудивительно, что природа создала здесь...; Стоит ли удивляться, что такие события происходят и сегодня...), а также эмоционально окрашенные высказывания (доминирование рациональной оценки над эмоциональной) с маркером восклицательности (примеры (13) и (14)).

(13) А еще через некоторое время вода закипит!

(14) Оно примерно в сто тысяч раз меньше атома!

Наряду с представленной моделью в учебном тексте реализуется модель $\mathbf{P}$ caus $\rightarrow \mathbf{S}_{\mathbf{3}}\left(\mathbf{a в T o p )}+\mathbf{S}_{\mathbf{4}}\right.$ (читатель) feel $\mathbf{E m o}$, эмотивная окраска которой не отличаются от окраски модели с субъектом-адресантом. Однако для реализации данной модели необходимо эксплицировать в субъектной перспективе текста субъекта-адресата, например, посредством местоимений и форм глагола, как в примере (15) с эмоционально окрашенным высказыванием (доминирование рациональной оценки над эмоциональной) и в примере (16) с эмотивной модусной рамкой.

(15) Имы $\left[\mathrm{S}_{3}+\mathrm{S}_{4}\right]$ увидим: монета тоже падает быстрее перышка! (16) $K$ нашему $\left[\mathrm{S}_{3}+\mathrm{S}_{4}\right]$ удивлению, теперь ярче светит та лампа, на которой указана меньшая мощность.

Отметим, что, как правило, адресат эксплицируется в субъектной перспективе учебного текста посредством так называемых «средств, выражающих движение мысли» (Котюрова и др. 2015: 120), из которых следует выделить средства, выражающие активизацию мысли (Рассмотрим основные единицы...; Проведем анализ данных...), и «трафаретный» зачин (Вы уже знаете, что...; Как вы помните...). В подобных случаях эмоциональные переживания, воплощенные в других фрагментах завершенного текста, следует 
относить в том числе и к субъекту-адресату. Так, примеры (13) и (14) представлены в завершенном учебном тексте, в субъектной перспективе которого адресат не эксплицирован, а значит, носителем эмоционального состояния является только адресант. Если же, например, высказыванию (13) предшествовало бы высказывание типа Рассмотрим процесс кипения воды, то речь бы шла о реализации обсуждаемой модели $\mathbf{P}$ caus $\rightarrow \mathbf{S}_{3}$ (aвтор) $+\mathbf{S}_{4}$ (читатель) feel Emo.

Иногда в учебных текстах также встречается модель $\mathbf{P}$ caus $\rightarrow \mathbf{S}_{4}$ (читатель) feel Emo; особенно это характерно для учебников по обществознанию, из которых приведены примеры (17) и (18) с языком описания эмоций.

(17) Это [P] покажется вам $\left[\mathrm{S}_{4}\right]$ очень долгим и скучным.

(18) Твой бюджет составляют карманные деньги, выдаваемые родителями на неделю или на месяи. Ты $\left[\mathrm{S}_{4}\right]$ можешь истратить их в первый же день, а потом горько сожалеть, что не удалось сходить в кино $[\mathrm{P}] \ldots$

Модальные ЭС прежде всего связаны со стратегиями диалогизирования текста (Трущелёв 2019), которые, в свою очередь, обусловливают «диалоговый характер» учебного текста (Холодная, Гельфман 2016: 40). Эмоциогенность этой характеристики учебного текста всегда подчеркивалась отечественными специалистами (Там же). Кроме того, модальные ЭС, тематизирующие эпистемические эмоции, могут быть направлены на эмоциональное заражение читателя.

\section{Вербализация эмоционального сценария интереса}

Проведенный нами анализ учебных текстов позволяет выделить особый прием создания эмотивности текста - вербализацию эмоционального сценария интереса, проецированного на адресата.

По всей видимости, идея о проецировании эмоциональных сценариев принадлежит Ф. Маканю (Macagno 2014). Опираясь на когнитивные теории эмоций, ученый предположил, что в тексте могут быть представлены готовые оценки тех или иных событий (например, посредством оценочных прилагательных), которые могут стать причиной появления у адресата оценочных суждений, лежащих в основе эмоциональных реакций (Macagno 2014: 115). На наш взгляд, такой подход можно расширить, если учитывать не только оценочные суждения адресата, но и другие составляющие эмоционального сценария интереса (см. об этих составляющих в Апресян В.Ю., Апресян Ю.Д. 1995), а именно то, как эмоция интереса проявляется в познавательной деятельности ее субъекта.

Считаем такой подход более плодотворным, поскольку в современной психологии многие положения когнитивных теорий эмоций становятся дискуссионными. Все большое признание получает мотивационно-когнитивный 
подход к эмоциям, согласно которому эмоции трактуются как результат интеграции убеждений (знаний) индивида и целей текущей деятельности (Miceli \& Castelfranchi 2015: 8). Оценочные суждения являются лишь производным от этих составляющих и необязательным компонентом эмоции (Ibid.: 13). Нельзя не отметить, что деятельностный аспект эмоциональных переживаний индивида не только всегда подчеркивался в отечественных психологических исследованиях, но и являлся отправным при изучении эмоций (Рубинштейн 2001: 551-554, Юматов и др. 2017: 14-29).

Модель ЭС при вербализации эмоционального сценария интереса можно представить следующим образом: $\mathbf{P}$ caus $\rightarrow \mathbf{S}_{4}$ (читатель) feel Emo (интеpec), где P - определенное содержание учебного текста, являющееся объектом познавательной деятельности. Однако в данном случае субъект-адресат не всегда эксплицируется в тексте, а его эмоциональное переживание интереса идентифицируется по характерным признакам познавательной деятельности, которые фиксируются в тексте.

Важно также отметить, что рассмотренные выше модальные ЭС с субъектом-адресатом не могут быть в полной мере отнесены к способам вербализации эмоционального сценария интереса. С одной стороны, эти ситуации, являясь приемом диалогизирования учебного текста, способны включить читателя-школьника «в качестве "соучастника" в интеллектуальный поиск» (Холодная, Гельфман 2016: 40). Однако, с другой стороны, сами по себе эти приемы не фиксируют в содержании текста процесс «интеллектуального поиска». Таким образом, они могут рассматриваться как вспомогательные средства вербализации эмоционального сценария интереса.

В проанализированных нами учебных текстах представлен лишь один способ вербализации эмоционального сценария интереса, каузирующий оценочные суждения адресата, - модель Вы + глагол в форме буд. вр. (часто ментальный глагол): вы научитесь работать...; вы расширите свои знания о...; вы будете изучать...; вы познакомитесь... Данный способ, в котором всегда эксплицируется субъект-адресат, направлен на формирование оценки новизны учебного текста, которая, в свою очередь, может стать причиной появления интереса (Silvia 2006: 57). В то же время такая объективная оценка новизны учебного текста в бо́льшей степени относится к автору текста, а значит, формирование субъективной оценки у адресата может потребовать дополнительных средств (например, вы узнаете о многих удивительных открытиях).

Следующий способ - указание на значимость, актуальность определенной информации для адресата (важнне значение имеют знания о...; ...важнно понимать причины этих событий; ...без этих знаний невозможнно представить сегодняшнюю жизнь). Данный способ связан с формированием у адресата убеждений в значимости информации, представленной в учебном тексте, что также оказывает влияние на интерес (Schiefele 2009). Следует учесть, что 
подобные указания свидетельствуют о рациональном подходе к предоставлению информации в тексте и в большей степени могут воздействовать на человека в более зрелом возрасте, а не на читателя-подростка.

Другой способ вербализации эмоционального сценария интереса использование так называемых «объяснительных вопросов» ${ }^{14}$ (примеры (19) и (20)), т.е. вопросов, обращенных к последующему содержанию текста, ответы на которые, по мнению автора текста, хочет получить адресат (Sperber \& Wilson 1996: 252).

(19) Как же ориентироваться в огромном многообразии организмов?

(20) Как в старину объясняли закономерности природных явлений?

Такие вопросы отражают одну из деятельностных особенностей эмоции интереса - желание узнать что-то новое об объекте интереса. Так, по мнению С.А. Ушаковой (Шишкиной), «ментальное состояние интереса <..> соотносится с речевым актом вопроса» (Ушакова 2003: 53).

Особое внимание следует уделить проецированию ненормальных ситуаций на адресата. Такой прием часто используется в учебниках по физике и обществознанию.

Рассмотрим два характерных примера.

(21) Казалось бы, ответить на вопрос, движется какое-либо тело или покоится, очень просто. Например, если вы сидите сейчас дома у окна, то вы покоитесь, а автомобиль, едущий мимо вашего окна, движется. Однако та же ситуаџия выглядит по-другому с точки зрения пассажира автомобиля, который проезжает мимо вашего дома. Он может считать, что он покоится, а вы вместе с домом движетесь.

Кроме того, вы оба вместе с пассажиром автомобиля находитесь на Земле, которая совершает суточное вращение вокруг своей оси и летит по орбите вокруг Солнца со скоростью около $30 \mathrm{\kappa м} / \mathrm{c}$.

(22) По-видимому, все вещества состоят из отдельных частичек, между которыми имеются промежутки. Если частицы удаляются друг от друга, то объем тела увеличивается. И наоборот, когда частищы сближаются, объем тела уменьшается.

Тогда возникает вопрос: если все тела состоят из мельчайших частии, почему они кажутся нам сплошными (например, железо, вода, стекло, дерево)?

Современная наука доказала, что частицыь вещества так маль, что мы их не видим.

В примере (21) ненормальная ситуация реализуется в первую очередь посредством противопоставления ирреальной и реальной модальностей. В первом абзаце можно выделить модальную ситуацию «ситуативно обусловленной возможности» (вводное слово казалось) со значением предположительности (частицы быl). Данная ситуация возможности обусловлена имеющимися у адресата фоновыми знаниями. Однако в следующих двух абзацах

14 “expository questions" (Sperber \& Wilson 1996: 252). 
демонстрируется несостоятельность представленной точки зрения, чему способствует использование противительного союза однако и наречия по-другому. Кроме того, такое противопоставление осуществляется и с помощью грамматически организованной субъектной перспективы, которая отражает смену точек зрения: aдресат $\rightarrow$ пассажир автомобиля $\rightarrow$ Солнще.

В примере (22) в субъектной перспективе представлены сразу два субъекта модуса - адресант и адресат, выраженные с помощью форм личного местоимения $\boldsymbol{M b l . ~ В ~ п е р в о м ~ в ы с к а з ы в а н и и ~ в ы р а ж е н о ~ з н а ч е н и е ~ п р е д п о л о ж и - ~}$ тельности (вводное слово по-видимому), однако далее высказанное предположение не оспаривается. Ненормальная ситуация же создается автором с помощью «объяснительного вопроса», который словно возникает у адресата в результате интеграции новых знаний, полученных из первого абзаца, и «наивных» фоновых знаний. Эта интеграция отражена в самой структуре условно-вопросительной конструкции, в условной части которой (если все тела состоят из мельчайших частиц...) фиксируется уже известный читателю фрагмент знаний.

Как видно, в обоих фрагментах суть ненормальности проецируемых на адресата ситуаций заключается в несоответствии знаний учащихся реальному положению дел и, следовательно, в желании это несоответствие разрешить. Поскольку именно несоответствие наших ожиданий реальному положению дел лежит в основе эмоции интереса, запускающей познавательную деятельность (Miceli \& Castelfranchi 2015: 56), полагаем, что проецированные на адресата ненормальные ситуации являются одним из способов вербализации эмоционального сценария интереса.

Примеры (21) и (22) демонстрируют, что одним из основных способов создания проецированных на адресата ненормальных ситуаций - это использование объяснительных вопросов и средств выражения модальных значений. Для бо́льшей наглядности приведем еще один пример.

(23) Мы говорим: грязные руки, грязный двор, грязный город. А можно ли сказать: грязный воздух, грязная вода, грязный лес, грязная земля? К сожалению, можно. Точнее так: загрязненный воздух, загрязненньй лес, загрязненная вода и почва.

В данном фрагменте адресат вновь эксплицирован совместно с адресантом в субъектной перспективе текста (местоимение $\boldsymbol{M b l}$ ). Ирреальная модальность представлена категориальной ситуацией возможности, однако на этот раз это ситуация «разрешения», о чем свидетельствуют формы глагола мочь (Бондарко и др. 1990: 135). Объяснительный вопрос вновь следует за высказыванием, в котором фиксируется некий известный для читателя фрагмент знаний.

Важно сказать, что все приемы проецирования ненормальных ситуаций на читателя связаны с так называемой «проблемной формой изложения учебного материала» (Холодная, Гельфман 2016: 37). Так, М.А. Холодная и Э.Г. Гельфман выделяют две главные особенности такой формы изложения: 
1) «...наличие в тексте проблемной ситуации с выделением того противоречия, которое не может быть разрешено на основе прошлых знаний» (Там же: $38)$; 2) «...включение проблемных вопросов, которые "разворачивают" проблемную ситуацию в различных, часто неожиданных для ученика контекстах» (Там же). Несмотря на то что обсуждение проблемных форм изложения уже давно занимает отечественных педагогов, они до сих пор не были предметом детального изучения лингвистов.

На наш взгляд, вербализация эмоционального сценария интереса является одним из способов тематизации этой эмоции и, следовательно, направлена в первую очередь на эмоциональное заражение читателя.

\section{6. Заключение}

1. В ситуациях речевого взаимодействия намерение адресанта каузировать эмоцию интереса у адресата лежит в основе создания эмоционально-эвокативного типа учебного дискурса. В данном типе дискурса используются стратегии развертывания текста, ориентированные на каузацию интереса (interest-evoking rhetorical strategies). Ряд таких стратегий основывается на передаче в речи эмоций как особого типа информации (дискурс об эмоциях и собственно эмотивный дискурс).

2. В учебном тексте как продукте речевой деятельности данный тип информации представлен эмотивностью текста - компонентом его смысловой структуры, посредством которого манифестируются (описываются и выражаются) эмоциональные переживания. Такая манифестация связана с реализацией нескольких конкретных стратегий и приемов, нацеленных на увеличение потенциальной эмоциогенности текста.

3. Манифестация эмоциональных переживаний персонажей текста, или субъектов диктума, прежде всего связана со стратегиями усиления наглядности, яркости изложения. Повышая эмоциогенность учебного текста, такие стратегии, как правило, значительно детализируют изложение и продуцируют седактивные детали (интересную, но незначимую информацию) в смысловой структуре текста. Кроме того, такие стратегии требуют идентификации субъекта эмоций, а потому используются преимущественно в текстах с элементами повествования (чаще всего в учебниках по истории).

4. Для увеличения динамичности и неожиданности («сюрпризности») учебного текста авторы могут реализовать в тексте особые эмоциональные сценарии, в которых субъекты диктума испытывают эмоции, - ненормальные ситуации. Эти ситуации основаны на нарушении ожидаемых отношений между компонентами действительности (пространственных, причинных и др.), отраженных в содержании текста.

5. Манифестация эмоциональных переживаний участников коммуникации, или субъектов модуса связана со стратегиями диалогизирования, нацеленного на формирование диалогового характера учебного текста, и тематизации эмоции интереса, направленной на эмоциональное заражение читателя. 
Проведенный нами анализ показал, что именно эти стратегии шире всего используются в учебных текстах по всем дисциплинам - русскому языку, обществознанию, истории, биологии и физике.

6. Особой стратегией тематизации эмоции интереса считаем вербализацию эмоционального сценария интереса, проецированного на адресата. Данная стратегия осуществляется посредством фиксации в тексте характерных во время переживания эмоции интереса признаков познавательной деятельности адресата, главные из которых - желание узнать что-то новое об объекте интереса и оценка его значимости и новизны.

\section{Благодарности и финансирование}

Авторы выражают благодарность анонимным рецензентам статьи, советы и замечания которых способствовали дополнительным размышлениям над предлагаемой концепцией и способами ее представления в статье.

Исследование выполнено при финансовой поддержке РФФИ в рамках научного проекта № 20-012-00284 («Психолингвистическое исследование эмоциогенности учебных текстов (формирование эмоции интереса)»).

(C) Larisa A. Piotrovskaya and Pavel N. Trushchelev, 2020
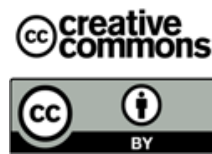

This work is licensed under a Creative Commons Attribution 4.0 International License https://creativecommons.org/licenses/by/4.0/

\section{СПИСОК ЛИТЕРАТУРЫ / REFERENCES}

Аверьянова Е.Н. Средства выражения семантики внезапности в сообщениях об отклонении от нормы ожидания (на материале текстов художественной литературы) [Электронный ресурс] // Вестник Майкопского государственного технологического университета. 2010. № 4. http://lib.mkgtu.ru/images/stories/journal-vmgtu/2010-04/017.pdf. (дата обращения: 15.03.2020). [Averyanova, Elena N. 2010. Means of Expression of Suddenness Semantics in the Reports of Abnormal Expectations (on the Example of Fiction Texts). Vestnik Maikopskogo gosudarstvennogo tekhnologicheskogo universiteta 4. http://lib.mkgtu.ru/images/stories/journal-vmgtu/2010-04/017.pdf. (accessed 15 March 2020). (In Russ.)].

Апресян В.Ю., Апресян Ю.Д. Метафора в семантическом представлении эмоций // Апресян Ю.Д. Избранные труды: т. 2: интегральное описание языка и системная лексикография. М.: Языки русской культуры, 1995. С. 453-465. [Apresyan, Valeriya Yu. \& Apresyan Yurii D. 1995. Metafora v semanticheskom predstavlenii emotsii (Metaphor in Semantic Representation of Emotions). In Yurii D. Apresyan, Izbrannye Trudy. Tom 2. Integral'noe opisanie yazyka i sistemnaya leksikografiya. 453-465. Moscow: Yazyki Russkoi Kul'tury. (In Russ.)].

Бабенко Л.Г. Лексические средства обозначения эмоций в языке. Свердловск: изд-во Урал. ун-та, 1989. [Babenko, Lyudmila G. 1989. Leksicheskie sredstva oboznacheniya emotsii v yazyke (Lexical Means of Denoting Emotions in the Russian Language). Sverdlovsk: Ural State University Publishing house. (In Russ.)]. 
Болотов В.И. Эмоциональность текста в аспектах языковой и неязыковой вариативности: основы эмотивной стилистики текста. Ташкент: Фан, 1981. [Bolotov, Vladimir I. 1981. Emotsional'nost' teksta v aspektakh yazykovoi i neyazykovoi variativnosti. Osnovy emotivnoi stilistiki teksta (The Emotionality of Text in Aspects of Linguistic and Non-Linguistic Variability. The Basics of Emotional Style of a Text). Tashkent: Fan. (In Russ.)].

Бондарко А.В., Беляева Е.И., Бирюлин Л.А., Корди Е.Е., Сильницкий Г.Г., Храковский В.С., и др. Теория функциональной грамматики: темпоральность, модальность. Редкол.: А.В. Бондарко (отв. ред.) [и др.]. Л.: Наука, 1990. [Bondarko, Aleksandr V., Belyaeva, Elena I., Biryulin, Leonid A., Kordi, Elena E., Sil'nitskii, Georgii G., Khrakovskii, Viktor S., et al. 1990. Teoriya funktsional'noi grammatiki. Temporal'nost', modal'nost' (The Theory of Functional Grammar. Temporality, modality). Leningrad: Nauka. (In Russ.)].

Вотякова И.А. О концепте «удивление» в русской языковой картине мира // Вестник удмуртского университета. Сер. «История и филология». 2015. № 3. С. 120-124. [Votyakova Irina A. 2015. On the Concept «Surprise» in the Russian Language Picture of the World. Bulletin of Udmurt University. Series History and Philology 3. 120-124. (In Russ.)].

Залевская А.А. Текст и его понимание. Тверь: Твер. гос. ун-т, 2001. [Zalevskaya, Aleksandra A. 2001. Tekst i ego ponimanie (Text and its Comprehension). Tver: Tver State University Publishing house. (In Russ.)].

Зимняя И.А. Лингвопсихология речевой деятельности. М.: МОДЭК, 2001. [Zimnyaya, Irina A. 2001. Lingvopsikhologiya rechevoi deyatel'nosti (Linguo-Psychology of Performance). Moscow: MODEK. (In Russ.)].

Золотова Г.А., Онипенко Н.К., Сидорова М.Ю. Коммуникативная грамматика русского языка. М.: Ин-т рус. яз., 2004. [Zolotova, Galina A., Onipenko, Nadezhda K. \& Sidorova, Mariya Yu. 2004. Kommunikativnaya grammatika russkogo yazyka (Communicative Grammar of the Russian Language). Moscow: Institute of the Russian language Publishing house. (In Russ.)].

Ионова С.В. Эмоциональные эффекты позитивной формы общения // Вестник Российского университета дружбы народов. Сер.: Лингвистика. 2015. № 1. С. 20-30. [Ionova, Svetlana V. 2015. Emotional effects of positive forms of communication. Russian Journal of Linguistics 1, 966-987. (In Russ.)].

Кибрик А.А. Модус, жанр и другие параметры классификации дискурсов // Вопросы языкознания. 2009. № 2. С. 3-21. [Kibrik, Andrei A. 2009. Modus, zhanr i drugie parametry klassifikatsii diskursov (Modus, genre, and other parameters of discourses classification), Voprosy Jazykoznanija 2. 3-21. (In Russ.)].

Котюрова М.П., Дмитриева К.В., Соловьева Н. В. Выражение диалогичности речи в научно-учебных текстах // Русский язык и литература в пространстве мировой культуры: мат. XIII конгресса Междунар. ассоц. преподав. рус. яз. (г. Гранада, 20 сентября 2015 г.). Редкол.: Л.А. Вербицкая [и др.]. СПб.: Междунар. ассоц. преподав. pус. яз., 2015. С. 119-123. [Kotyurova, Mariya P., Dmitrieva, Kristina V. \& Solov'eva Natal'ya V. 2015. Vyrazhenie dialogichnosti rechi v nauchno-uchebnykh tekstakh (The Expression of Dialogic Speech in Expository Texts). In Lyudmila A. Verbitskaya, et al. (eds.), Russkii yazyk $i$ literatura $v$ prostranstve mirovoi kul'tury, 119-123. Saint Petersburg: Mezhdunarodnaya assotsiatsiya prepodavatelei russkogo yazyka. (In Russ.)].

Маслова В.А. Параметры экспрессивности текста // Человеческий фактор в языке: языковые механизмы экспрессивности. Отв. ред. В. Н. Телия. М.: Наука, 1991. С. 179 204. [Maslova, Valentina A. 1991. Parametry ekspressivnosti teksta (The Options of Text 
Expressivity). In Veronika N. Teliya (ed.), Chelovecheskii faktor v yazyke. Yazykovye mekhanizmy ekspressivnosti, 179-204. Moscow: Nauka. (In Russ.)].

Онипенко Н.К. Модель субъектной перспективы и проблема классификации эгоцентрических элементов // Проблемы функциональной грамматики: принцип естественной классификации. Отв. ред. А. В. Бондарко, В. В. Казаковская. М.: Языки славянской культуры, 2013. С. 92-121. [Onipenko, Nadezhda K. 2013. Model of Subject Perspective and Classification of Egocentric Elements. In Aleksandr V. Bondarko \& Viktoriya V. Kazakovskaya (eds.), Problemy funktsional'noi grammatiki: printsip estestvennoi klassifikatsii, 92-121. Moscow: Yazyki slavyanskoi kul'tury. (In Russ.)].

Пиотровская Л.А. Эмотивные высказывания как объект лингвистического исследования: (на материале русского и чешского языков). СПб.: изд-во С.-Петерб. ун-та, 1994. [Piotrovskaya, Larisa A. 1994. Emotivnye vyskazyvaniya kak ob"ekt lingvisticheskogo issledovaniya: (na materiale russkogo i cheshskogo yazykov) (Emotive Utterance as an Object of Linguistic Study (Based on Russian and Czech)). Saint Petersburg: Saint Petersburg State University Publishing house. (In Russ.)].

Пиотровская Л.А. Эмоции в языке и речевой деятельности: описание, выражение и отражение эмоций // Когнитивные исследования языка. 2015. Вып. 22: Язык и сознание в междисциплинарной парадигме исследований: материалы Междунар. конгресса по когнитивной лингвистике, 30 сент.-2 окт. 2015. Отв. ред. Т.А. Клепикова. C. 776-781. [Piotrovskaya, Larisa A. 2015. Emotsii v yazyke i rechevoi deyatel'nosti: opisanie, vyrazhenie i otrazhenie emotsii (Emotions in Language and Language Behavior: Description, Expression and Reflection). In Tatiana A. Klepikova (ed.), Kognitivnye issledovaniya yazyka. Vol. 22. Yazyk $i$ soznanie $v$ mezhdistsiplinarnoi paradigme issledovanii, 776-781. (In Russ.)].

Пиотровская Л.А., Трущелёв П.Н. Конкретизация учебного текста как способ формирования интереса у читателя (на примерах описания природы) // Печать и слово СанктПетербурга (Петербургские чтения - 2018): сб. науч. тр. ХIX Всероссийской науч. конф. Редкол.: Н.Б. Лезунова [и др.]. СПб.: СПбГУПТД, 2018. С. 305-311. [Piotrovskaya, Larisa A. \& Trushchelev, Pavel N. 2018. The Training Text Concretization as a Way to Evoke Reader's Interest (Nature Description for Examples). In Natal'ya B. Lezunova, et al. (eds.), Pechat' i slovo Sankt-Peterburga (Peterburgskie chteniya 2018), 305-311. Saint Petersburg: SPbGUPTD, (In Russ.)].

Пиотровская Л.А., Трущелёв П.Н. Экспериментальное исследование эмоциогенности текстов (формирование интереса в учебном тексте) // Известия Российского государственного педагогического университета им. А.И. Герцена. 2019. № 192. С. 112123. [Piotrovskaya, Larisa \& Trushchelev, Pavel. 2019. An Experimental Investigation of Text Emotiogenicity (formation of interest in a school text). Izvestia: Herzen University Journal of Humanities \& Sciences 192. 112-123. (In Russ.)].

Рубинштейн С.Л. Основы общей психологии. 5-е изд. СПб.: Питер, 2001. [Rubinshtein, Sergei L. 2001. Osnovy obshchei psikhologii (Foundations of General Psychology). 5th edn. Saint Petersburg: Piter. (In Russ.)].

Трущелёв П.Н. Диалогизирование учебного текста как средство формирования интереса учащихся // Русская литература и диалог культур в эпоху глобализации: материалы II Всероссийской студенч. науч.-практ. конф. 19, 20 октября 2018. Редкол.: Е.И. Лелис (отв. ред.) [и др.]. СПб.: СПбГИКиТ, 2019. С. 109-114. [Trushchelev, Pavel N. 2019. Dialogizirovanie uchebnogo teksta kak sredstvo formirovaniya interesa uchashchikhsya (Dialogization of Expository Text to Learners' Interest Evoking). In Elena I. Lelis (ed.), Russkaya literatura i dialog kul'tur v epokhu globalizatsii. 109-114. Saint Petersburg: SPbGIKiT. (In Russ.)]. 
Ушакова С.А. Интенциональное состояние интереса и его выражение в английском языке // Международная филологическая конференция: Материалы XXIII международной филологической конференции: Вып. 3. Лексикология и фразеология (романо-германский цикл). СПб.: изд-во С.-Петерб. ун-та, 2003. С. 51-53. [Ushakova, Svetlana A. 2003. Intentsional'noe sostoyanie interesa i ego vyrazhenie v angliiskom yazyke (The Intentional State of Interest and its Expression in English). Mezhdunarodnaya filologicheskaya konferentsiya. Vyp. 3. Leksikologiya i frazeologiya, 51-53. Saint Petersburg: Saint Petersburg State University Publishing house. (In Russ.)].

Филимонова О.Е. Эмоциология текста: анализ репрезентации эмоций в английском тексте. СПб.: Книжный Дом, 2007. [Filimonova, Ol'ga E. 2007. Emotsiologiya teksta. Analiz reprezentatsii emotsii v angliiskom tekste (Emotiology of the Text. Analysis of the Representation of Emotions in the English Text). Saint Petersburg: Knizhnyi dom. (In Russ.)].

Холодная М.А., Гелфман Э.Г. Развивающие учебные тексты как средство интеллектуального воспитания учащихся. М.: Ин-т психологии Рос. акад. наук, 2016. [Kholodnaya, Maria A. \& Gelfman, Emanuila G. 2016. Razvivayushchie uchebnye teksty kak sredstvo intellektual'nogo vospitaniya uchashchikhsya (Developing educational texts as a means of students intellectual education). Moscow: Institut psikhologii RAN. (In Rus.)].

Шаховский В.И. Категоризация эмоций в лексико-семантической системе языка. 3-е изд. М.: УРСС, 2009. [1987]. [Shakhovskii, Victor I. 2009/1987. Kategorizatsiya emotsii v leksiko-semanticheskoi sisteme yazyka (Emotion categorization in the language lexical semantical system) 3rd edn. Moscow: URSS. (In Russ.)].

Шаховский В.И. Лингвистическая теория эмоций. М.: Гнозис, 2008. [Shakhovskii, Victor I. 2008. Lingvisticheskaya teoriya emotsii (The Linguistic Theory of Emotions). Moscow: Gnozis. (In Russ.)].

Юматов Е.А., Глазачев О.С., Быкова Е.В., Дудник Е.Н., Потапова О.В., Перцов С.С. Психофизиология эмоций и эмоционального напряжения студентов. М.: ИТРК, 2017. [Yumatov, Evgenii A., Glazachev, Oleg S., Bikova, Elena V., Dudnik, Elena N., Potapova, Ol'ga V., \& Pertsov, Sergei S. 2017. Psychophysiology of emotions and emotional stress of the students. Moscow, ITRC. (In Russ.)].

Alba-Juez, Laura 2016. Discourse Analysis and Pragmatics: Their Scope and Relation. Russian Journal of Linguistics 20 (4). 43-55. DOI: 10.22363/2312-9182-2016-20-4-43-55.

Alba-Juez, Laura \& Larina, Tatiana. 2018. Language and Emotion: Discourse-Pragmatic Perspectives. Russian Journal of Linguistics 22 (1). 9-37. DOI: 10.22363/2312-91822018-22-1-9-37.]

Alba-Juez, Laura \& Mackenzie, J. Lachlan. 2019. Emotions in Discourse. In Laura Alba-Juez \& J. Lachlan Mackenzie (eds.), Emotion processes in discourse, 3-27. Amsterdam/ Philadelphia: John Benjamins Publishing Company. DOI: 10.1075/pbns.302.01alb.

Eitel, Alexander \& Kühl, Tim (eds.). 2019. Harmful or Helpful to Learning? Boundary Conditions of Seductive Details Effects on Cognitive and Affective Processing of Instruction. [Special issue]. Applied Cognitive Psychology, 33 (1).

Daneš, František. 1982. Intonace v textu (promluvě). Slovo a slovesnost 2. 83-100. (In Czech). Edwards, Derek. 1999. Emotion Discourse. Culture \& Psychology 5 (3). 271-291. DOI: 10.1177/1354067X9953001.

Hidi, Suzanne \& Baird, William. 1988. Strategies for Increasing Text-Based Interest and Students' Recall of Expository Texts. Reading Research Quarterly 23 (4). 465-483. DOI: $10.2307 / 747644$.

Hidi, Suzanne, \& Renninger, K. Ann. 2006. The Four-Phase Model of Interest Development. Educational Psychologist 41(2). 111-127. DOI: 10.1207/s15326985ep4102_4. 
Izard, Carroll E. 2007. Basic Emotions, Natural Kinds, Emotion Schemas, and a New Paradigm. Perspectives on Psychological Science 3. 260-280. DOI: 10.1111/j.17456916.2007.00044.x.

Kaakinen, Johanna K., Papp-Zipernovszky, Orsolya, Werlen, Egon, Castells Gomez, Nuria, Bergamin, Per B., Baccino, Thierry, et al. 2018. Learning to Read in a Digital World. In Mirit Barzillai, Jenny Thomson, Sascha Schroeder, \& Paul van den Broek (eds.), Emotional and Motivational Aspects of Digital Reading, 143-166. Amsterdam/ Philadelphia: John Benjamins Publishing Company. DOI: 10.1075/swll.17.06kaa.

Katriel, Tamar. 2015. Methods of Exploring Emotions. In Helena Flam \& Jochen Kleres (eds.), Exploring Emotion Discourse, 57-66. London/New York: Routledge.

Kintsch, Walter. 1980. Learning from Text, Levels of Comprehension, or: Why Anyone Would Read a Story Anyway. Poetics 9. 87-98. DOI: 10.1016/0304-422X(80)90013-3.

Koschut, Simon. 2018. Researching Emotions in International Relations: Methodological Perspectives on the Emotional Turn. In Maeva Clement \& Eric Sangar (eds.), Speaking from the Heart: Emotion Discourse Analysis in International Relations, 277-301. Cham: Palgrave Macmillan. DOI: 10.1007/978-3-319-65575-8_12.

Macagno, Fabrizio. 2014. Manipulating Emotions. Value-Based Reasoning and Emotive Language. Argumentation and Advocacy 51. 103-122. DOI: 10.1080/00028533. 2014.11821842.

Miceli, Maria \& Castelfranchi, Cristiano. 2015. Expectancy and Emotion. Oxford: Oxford University Press.

Rey, Gunter D. 2012. A Review of Research and a Meta-Analysis of the Seductive Detail Effect. Educational Research Review 7. 216-237.

Schiefele, Ulrich. 2009. Situational and Individual Interest. In Kathryn R. Wentzel \& Allan Wigfield (eds.), Handbook of Motivation at School, 197-222. New York: Routledge.

Schraw, Gregory \& Lehman, Stephen. 2001. Situational Interest: A Review of the Literature and Directions for Future Research. Educational Psychology Review, 13 (1). 23-52. DOI: 10.1023/A:1009004801455.

Silvia, Paul J. 2006. Exploring the Psychology of Interest. New York: Oxford University Press. Sperber, Deirdre \& Wilson, Dan. 1996. Relevance: Communication and Cognition. 2nd edn. Oxford/Cambridge: Blackwell.

Stankiewicz, Edward. 1964. Approaches to Semiotics: Cultural Anthropology, Education, Linguistics, Psychiatry, Psychology. In Thomas A. Sebeok, Alfred S. Hayes, \& Mary C. Bateson (eds.), Problems of Emotive Language, 239-264. The Hague/Paris: Mouton \& Co.

van Dijk, Teun A. 2014. Discourse and knowledge. Cambridge: Cambridge University Press. Volek, Bronislava. 1987. Emotive Signs in Language and Semantic Functioning of Derived Nouns in Russian. Amsterdam/Philadelphia: John Benjamins Publishing Company.

Wade, Suzanne E. 2001. Research on Importance and Interest: Implications for Curriculum Development and Future Research. Educational Psychology Review 13 (3). 243-261. DOI: $10.1023 / \mathrm{A}: 1016623806093$.

\section{Article history:}

Received: 30 July 2020

Revised: 20 November 2020

Accepted: 25 November 2020 


\section{История статьи:}

Дата поступления в редакцию: 30 июля 2020

Дата принятия к печати: 25 ноября 2020

\section{Bionote:}

Larisa A. PIOTROVSKAYA is Dr. (Advanced Doctorate), professor at Herzen State Pedagogical University of Russia; author of over 200 publications. Her research interests are focused on psycholinguistics, linguistics of emotions, intonation, Slavic studies, and pragmatics.

\section{Contact information:}

E-mail: larisa11799@yandex.ru

ORCID ID: 0000-0003-0195-5194

Pavel N. TRUSHCHELEV is PhD student at the Department of Russian Language at Herzen State Pedagogical University of Russia. His research interests include psycholinguistics, linguistics of emotions, pragmatics, and text linguistics.

\section{Contact information:}

E-mail: paveltrue2007@rambler.ru

ORCID ID: 0000-0003-0810-2434

\section{Сведения об авторах:}

Лариса Александровна ПИОТРОВСКАЯ - доктор филологических наук, професcop, профессор кафедры русского языка Российского государственного педагогического университета им. А. И. Герцена. Автор свыше 200 публикаций. Сфера научных интересов: психолингвистика, эмотиология, интонация, славистика, прагматика.

\section{Контактная информация:}

e-mail: larisa11799@yandex.ru

ORCID ID: 0000-0003-0195-5194

Павел Николаевич ТРУЩЕЛЁВ - аспирант кафедры русского языка филологического факультета Российского государственного педагогического университета им. А. И. Герцена. Сфера научных интересов: психолингвистика, эмотиология, прагматика, теория текста.

\section{Контактная информация:}

e-mail: paveltrue2007@rambler.ru

ORCID ID: 0000-0003-0810-2434 